Louisiana State University

LSU Digital Commons

8-1-2013

\title{
Natural variation and the capacity to adapt to ocean acidification in the keystone sea urchin Strongylocentrotus purpuratus
}

\author{
Morgan W. Kelly \\ University of California, Santa Barbara \\ Jacqueline L. Padilla-Gamiño \\ University of California, Santa Barbara \\ Gretchen E. Hofmann \\ University of California, Santa Barbara
}

Follow this and additional works at: https://digitalcommons.Isu.edu/biosci_pubs

\section{Recommended Citation}

Kelly, M., Padilla-Gamiño, J., \& Hofmann, G. (2013). Natural variation and the capacity to adapt to ocean acidification in the keystone sea urchin Strongylocentrotus purpuratus. Global Change Biology, 19 (8), 2536-2546. https://doi.org/10.1111/gcb.12251 


\title{
Natural variation and the capacity to adapt to ocean acidification in the keystone sea urchin Strongylocentrotus purpuratus
}

\author{
MORGAN W. KELLY ${ }^{1}$, JACQUELINE L. PADILLA-GAMIÑO ${ }^{1}$ and GRETCHEN E. HOFMANN \\ Department of Ecology, Evolution and Marine Biology, University of California, Santa Barbara, CA 93106-9620, USA
}

\begin{abstract}
A rapidly growing body of literature documents the potential negative effects of $\mathrm{CO}_{2}$-driven ocean acidification (OA) on marine organisms. However, nearly all this work has focused on the effects of future conditions on modern populations, neglecting the role of adaptation. Rapid evolution can alter demographic responses to environmental change, ultimately affecting the likelihood of population persistence, but the capacity for adaptation will differ among populations and species. Here, we measure the capacity of the ecologically important purple sea urchin Strongylocentrotus purpuratus to adapt to OA, using a breeding experiment to estimate additive genetic variance for larval size (an important component of fitness) under future high- $\mathrm{pCO}_{2} /$ low- $\mathrm{pH}$ conditions. Although larvae reared under future conditions were smaller than those reared under present-day conditions, we show that there is also abundant genetic variation for body size under elevated $\mathrm{pCO}_{2}$, indicating that this trait can evolve. The observed heritability of size was $0.40 \pm 0.32(95 \% \mathrm{CI})$ under low $\mathrm{pCO}_{2}$, and $0.50 \pm 0.30$ under high- $\mathrm{pCO}_{2}$ conditions. Accounting for the observed genetic variation in models of future larval size and demographic rates substantially alters projections of performance for this species in the future ocean. Importantly, our model shows that after incorporating the effects of adaptation, the OA-driven decrease in population growth rate is up to 50\% smaller, than that predicted by the 'no-adaptation' scenario. Adults used in the experiment were collected from two sites on the coast of the Northeast Pacific that are characterized by different $\mathrm{pH}$ regimes, as measured by autonomous sensors. Comparing results between sites, we also found subtle differences in larval size under high- $\mathrm{pCO}_{2}$ rearing conditions, consistent with local adaptation to carbonate chemistry in the field. These results suggest that spatially varying selection may help to maintain genetic variation necessary for adaptation to future OA.
\end{abstract}

Keywords: climate change, local adaptation, marine invertebrates, ocean acidification, quantitative genetics, rapid evolution

Received 17 April 2013; revised version received 17 April 2013 and accepted 1 May 2013

\section{Introduction}

Evolution can happen on rapid (ecological) timescales, and can prevent extinction following environmental change (Bell \& Gonzalez, 2009). However, few climate change studies have explicitly considered adaptation as a source of demographic resilience, focusing instead on geographic range shifts and the physiological tolerances of modern populations (Bradshaw \& Holzapfel, 2001; Etterson \& Shaw, 2001; Franks et al., 2007; Visser, 2008; Mitchell et al., 2011; Reed et al., 2011; Walters et al., 2012). In the absence of new mutations, evolutionary change depends on standing genetic variation, and so the magnitude of variation for physiological tolerance traits is likely to influence the risk of extinction in a changing environment (Hughes et al., 2008; Gomulkiewicz \& Houle, 2009). However, the extent of genetic variation for physiological tolerance is likely to

Correspondence: Morgan W. Kelly, tel. + 805893 6176, fax + 805893 4724, e-mail: morgan.kelly@lifesci.ucsb.edu ${ }^{1}$ These authors contributed equally to this work vary substantially across species and populations and cannot be generalized from theory or studies on model organisms (Hoffmann et al., 2003; Kelly et al., 2012). Consequently, the measurement of genetic variation for tolerance traits in natural populations has become an important priority for researchers seeking to forecast the biological impacts of climate change.

In marine ecosystems, organisms are threatened by both ocean warming and ocean acidification (OA) caused by the absorption of anthropogenic $\mathrm{CO}_{2}$ (Harley et al., 2006; Hofmann et al., 2010; Kroeker et al., 2010; Doney et al., 2012). Some studies have quantified genetic variation for heat tolerance (e.g. Eliason et al., 2011; Kelly et al., 2012; Sanford \& Kelly, 2010), but data on capacity for adaptation to low $\mathrm{pH}$ exist for only a handful of species (Collins \& Bell, 2006; Pistevos et al., 2011; Sunday et al., 2011; Foo et al., 2012; Lohbeck et al., 2012; Pespeni et al., 2013). Theory and previous work on temperature indicate that one of the most important forces maintaining adaptive variation for ecologically relevant traits is spatially varying selection (Hedrick, 2006; Mitchell-Olds et al., 2007). This suggests some 
cause for alarm with regards to the capacity of natural populations to adapt to OA, because current environmental gradients in $\mathrm{pH}$ may not be strong enough to maintain substantial adaptive variation for $\mathrm{pH}$ tolerance (Kelly \& Hofmann, 2012). The global gradient in temperature is large relative to the projected change, with a $30{ }^{\circ} \mathrm{C}$ difference in mean sea surface temperature between the poles and the equator and a projected $2.5^{\circ} \mathrm{C}$ change in temperature by 2100 (IPCC, 2007). This means that spatial variation in mean temperature within most species' geographic ranges is equal to or greater than the projected change in temperature, and this heterogeneity in temperature likely maintains genetic variation for thermal tolerance. By contrast, the global gradient in mean $\mathrm{pH}$ is small relative to the projected change from OA; both the global gradient and the projected change in mean $\mathrm{pH}$ over the next century are about $0.3 \mathrm{pH}$ units (Orr et al., 2005). As a result, natural populations may harbor relatively less adaptive variation for $\mathrm{pH}$ tolerance, than for temperature tolerance (Kelly \& Hofmann, 2012).

But even though global gradients in $\mathrm{pH}$ are small, regional-scale gradients might also act to maintain genetic variation. For example, on the Pacific coast of North America, wind-driven upwelling brings colder, more acidic waters to the surface (Hauri et al., 2012). Data from sensors deployed in the field indicate that organisms in these coastal upwelling habitats currently experience pulses of $\mathrm{pH}$ values not projected in the open ocean until the end of the century (Hofmann et al., 2011; Frieder et al., 2012). There is a latitudinal gradient in upwelling intensity in this region, with sites north of Point Conception experiencing stronger and more frequent upwelling, and lower annual $\mathrm{pH}$ minima than sites to the south (Hauri et al., 2012; Fig. 1). If this gradient is persistent enough, it is possible that populations of some species are locally adapted to these conditions, and could serve as a source of genotypes 'pre-adapted' to future $\mathrm{pH}$ regimes. Given the potential for local adaptation, it is especially important to consider more than one population when assessing the capacity for adaptation to OA, as individual populations may contain a smaller subset of the variation present at the species level (e.g. Kelly et al., 2012).

In the absence of new mutations, standing variation for $\mathrm{pH}$ tolerance in natural populations will determine the capacity for an evolutionary response to OA. However, natural variation for tolerance of high $\mathrm{pCO}_{2}$ has been measured for only a handful of species (Collins \& Bell, 2006; Pistevos et al., 2011; Sunday et al., 2011; Foo et al., 2012; Lohbeck et al., 2012), and to our knowledge, the possibility of local adaptation to $\mathrm{pH}$ has not been tested in any published study. Thus, to understand whether organisms may adapt to changes in $\mathrm{pH}$, the key unanswered questions are as follows: (i) how much genetic variation for $\mathrm{pH}$ tolerance exists within natural populations and (ii) how much variation is maintained by natural differences in $\mathrm{pH}$ conditions among populations? In this study, we compared the progeny of the ecologically important purple urchin Strongylocentrotus purpuratus (Pearse, 2006) from two locations on the US Pacific coast. We measured standing genetic variation for larval body size (an important component of fitness) under high $\mathrm{pCO}_{2}$, and tested the hypothesis that different upwelling regimes act to maintain variation among urchins from different sites in their tolerances of low$\mathrm{pH}$ conditions. By crossing male and female urchins from the two sites, we were able to separate the effects of sires (fathers), which are expected to contribute little more than genetic material, from the effects of dams (mothers), which contribute both genetic material and maternal effects (a form of transgenerational phenotypic plasticity). If there is genetic variation for size under high $\mathrm{pCO}_{2}$, we expected to see significant variation attributed to the effects of sires (fathers). If there is local adaptation to carbonate chemistry, we expected the offspring of sires from the northern site (with greater upwelling, longer low-pH events) to be larger under high $\mathrm{pCO}_{2}$ than the offspring of sires from the southern site.

\section{Materials and methods}

\section{Animal collection and sensor deployment}

We collected adult sea urchins from two sites in February, 2012: Santa Barbara Channel (SB, $\left.34^{\circ} 24.84 \mathrm{~N}, 119^{\circ} 59.06 \mathrm{~W}\right)$ at a depth of $5 \mathrm{~m}$ and Van Damme State Park (VD, 39 $16.72 \mathrm{~N}$, $123^{\circ} 48.17 \mathrm{~W}$ ) from the shallow subtidal zone (submerged in a surge channel during a spring low tide) (Fig 1A). We maintained all animals in aquarium facilities at UC Santa Barbara in flowing seawater, ambient temperatures $\left(15-16^{\circ} \mathrm{C}\right)$, and fed them kelp (Macrocystis pyrifera) ad libitum.

Sensors were deployed at four sites: two in northern California (BR, 38.07 ${ }^{\circ} \mathrm{N}, 123.32^{\circ} \mathrm{W}$; and $\mathrm{VD}, 39.28^{\circ} 123.80^{\circ} \mathrm{N}$; ) and two in southern California $\left(\mathrm{MR}, 34.39^{\circ} \mathrm{N}, 119.73^{\circ} \mathrm{W}\right.$; LOL $34.72^{\circ} \mathrm{N}, 120.61^{\circ} \mathrm{W}$ ) in 2011 and 2012 as part of a larger network of sensors making continuous measurements of $\mathrm{pH}$ and $\mathrm{pCO}_{2}$ at sites throughout the California Current Large Marine Ecosystem (CCLME, F. Chan, J. Barth, C. Blanchette, F. Chavez, O. Cheriton, G. Friederich, B. Gaylord, T. Gouhier, T. Hill, G. Hofmann, M. McManus, B. Menge, A. Russell, E. Sanford \& L. Washburn, unpublished data). Two of these sensors were in close proximity to the sampling locations; the VD sensor was within $50 \mathrm{~m}$ of the sampled adults, whereas the MR sensor was ca. $10 \mathrm{~km}$ from the adults sampled at the $\mathrm{SB}$ site. $\mathrm{pCO}_{2}$ was measured hourly at BR with a SAMI ${ }^{2}-\mathrm{CO}_{2}$ (Sunburst Sensors) deployed $1.2 \mathrm{~km}$ offshore, at a depth of $30 \mathrm{~m}$. $\mathrm{pCO}_{2}$ was estimated for MR from $\mathrm{pH}$, temperature, total alkalinity, and salinity. $\mathrm{pH}$ at $\mathrm{MR}, \mathrm{LOL}$, and VD was measured 
(a)
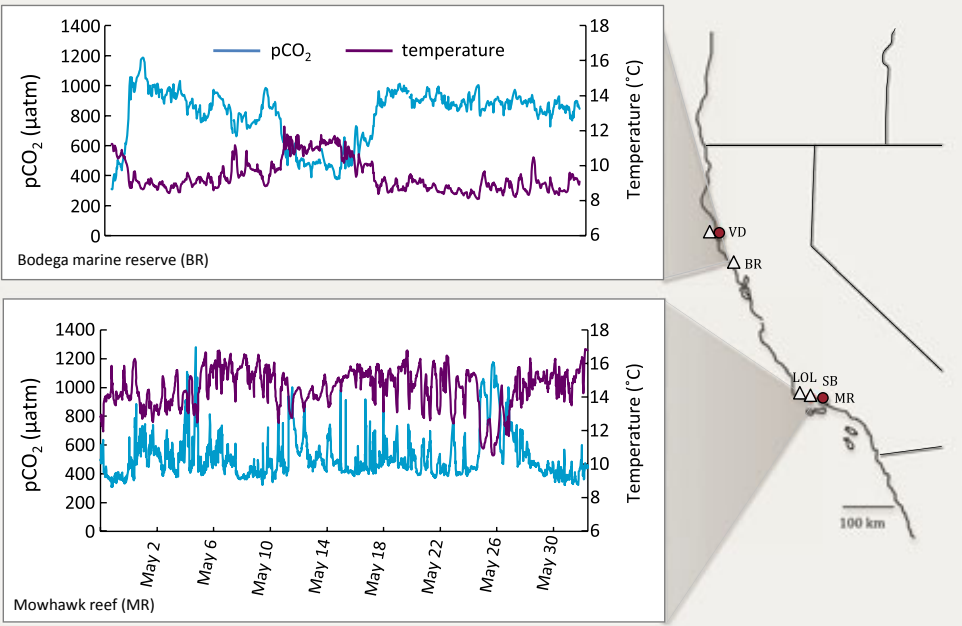

(b)

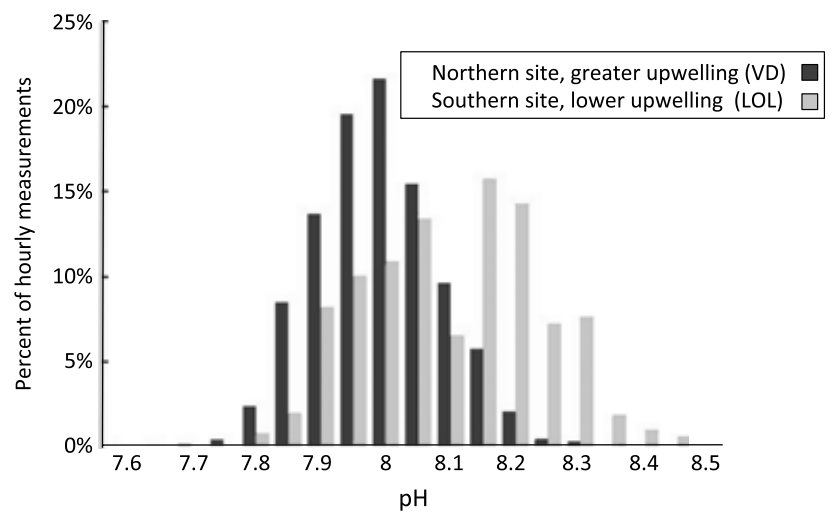

Fig. 1 A dissolved $\mathrm{CO}_{2}$ dynamics for May 2012 at two study sites, one in northern California, USA, and one in southern California. Triangles denote sensor locations (BR, $38.07^{\circ} \mathrm{N}, 123.32^{\circ} \mathrm{W} ; \mathrm{MR}, 34.39^{\circ} \mathrm{N}, 119.73^{\circ} \mathrm{W} ; \mathrm{VD}, 39.28^{\circ} \mathrm{N}, 123.80^{\circ} \mathrm{W} ; \mathrm{LOL}, 34.72^{\circ} \mathrm{N}, 120.61^{\circ} \mathrm{W}$ ), and circles denote Strongylocentrotus purpuratus collection locations (VD, $39.28^{\circ} \mathrm{N}, 123.80^{\circ} \mathrm{W} ; \mathrm{SB}, 34.41^{\circ} \mathrm{N}, 119.98^{\circ} \mathrm{W}$ ). Elevated pCO $\mathrm{cor}^{\circ}$ responds to lower $\mathrm{pH}$ values, with a $\mathrm{pCO}_{2}$ of $1200 \mu \mathrm{atm}$ corresponding to a $\mathrm{pH}$ of ca. 7.6 for the southern site. The northern site (BR) shows more persistent upwelling, with longer durations for high- $\mathrm{pCO}_{2} /$ low-temperature events. B. Histogram of hourly $\mathrm{pH}$ measurements at LOL (southern site) and VD (northern site) collected from May to September, 2011.

hourly with a modified version of the Honeywell DuraFET ${ }^{\circledR}$ (Honeywell, Fort Washington, PA, USA), an ion-sensitive field-effect transistor (ISFET), with an integrated data logger and power supply (modified from Martz et al., 2010). The MR sensor was deployed at $8 \mathrm{~m}$ depth, ca. $300 \mathrm{~m}$ offshore, and the VD and LOL sensors were deployed submerged in tide pools in the low intertidal zone.

\section{Spawning and crosses}

We induced spawning via intracoelomic injection of $0.5 \mathrm{M}$ $\mathrm{KCl}$. We collected eggs in $0.35 \mu \mathrm{m}$ filtered, UV sterilized seawater at ambient temperature, and $\mathrm{pCO}_{2}$ of $400 \mu \mathrm{atm}$. Sperm was collected dry, and kept on ice until fertilization. Crosses were made according to a modified North Carolina II design (Lynch \& Walsh, 1998, Supplemental Figure S1, Supplemental
Table S1). We crossed each male with four females, two from his own site and two from the other site. Each female was involved in two crosses: one with a male from her own site, and one with a male from the other site. We did this for a total of 8 males and 15 females from each site for a total of 64 crosses. We ran the experiment for eight consecutive weeks, culturing eight crosses split into two $\mathrm{pCO}_{2}$ treatments for each week of the experiment. Each week we created crosses from two males and two females from each site; sperm was stored on ice and used for two consecutive weeks of crosses. Storage on ice did not seem to affect fertility of sperm; we checked by microscope that we had achieved $100 \%$ fertilization success for each of the 64 crosses. Each week was treated as a separate block in the design for subsequent statistical analyses. Sires are assumed to contribute only genetic material, and so estimating the contribution of sires is critical to the estimation of 
additive genetic variance in a quantitative genetic breeding design. We split sperm from each male across two blocks of the experiment so as to be able to separately attribute variance to the effects of 'sires' and 'blocks'. However, eggs cannot be stored in this manner, so we used a different set of females for each week of crosses.

\section{Larval culturing and seawater chemistry}

We cultured larvae at densities of ca. 10 larvae $\mathrm{mL}^{-1}$ in a flow-through $\mathrm{CO}_{2}$-mixing system (Fangue et al., 2010), modified by pumping the appropriate $\mathrm{CO}_{2}$ gas mix for the treatment into the headspace of the culture ( $\mathrm{Yu}$ et al., 2011). $\mathrm{pCO}_{2}$ exposure levels were based on predictions for the California Current Large Marine Ecosystem, where anthropogenic inputs of $\mathrm{CO}_{2}$ are expected to drive surface $\mathrm{pH}$ down to 7.6 during upwelling in only a few decades (Gruber et al., 2012). Temperatures in sea water tables were held at $13{ }^{\circ} \mathrm{C}$ using a Delta Star ${ }^{\circledR}$ heat pump and a Nema $4 \mathrm{x}$ digital temperature controller (AquaLogic, San Diego, CA, USA). We measured temperature, salinity, and $\mathrm{pH}$ daily for each culture according to best-practice procedures outlined by Dickson et al. (2007), and described in detail in Fangue et al. (2010). Temperature, salinity, and carbonate parameters of seawater used in experimental treatments are shown in Table S2. We reared larvae for 5 days, just past the end of the nonfeeding stage, where larvae subsist on maternally provided yolk (Strathmann, 1987). While we did not explicitly measure survival, we did not observe evidence of mortality differences (e.g. visibly dead larvae or noticeable declines in density) between treatments.

\section{Morphometrics}

We measured body size (total skeletal length) for 3200 larvae ( $n=25$ per cross per treatment). Body size has been shown to decrease under high $\mathrm{pCO}_{2}$ in this and other species (Yu et al., 2011), and is an important component of larval fitness (Strathmann, 1971). We made morphometric measurements on photographs of pluteus-stage larvae (116 h after fertilization) oriented dorsal side down under $10 \times$ compound magnification. Skeletal length was measured as the distance from the spicule tip of the left postoral arm to the spicule tip of the aboral end. We tested for differences in skeletal length between treatments using a one-way ANOVA (in the statistical program $\mathrm{R}, 2010$ ) with $\mathrm{pCO}_{2}$ as a fixed factor. We tested that data met assumptions of ANOVA (normality, homogeneity of variance).

\section{Respirometry}

For a subset of families from each site, we estimated respiration under high and low $\mathrm{pCO}_{2}(n=6$ families for VD and 7 families for $\mathrm{SB}$ ). Rates of oxygen consumption were obtained in early pluteus larvae ( $92 \mathrm{~h}$ after fertilization for high and low $\mathrm{pCO}_{2}$ ) according to Marsh and Manahan (1999) with modifications. Different densities of larvae (50-600 individuals) were placed in each respiratory chamber $(684-795 \mu \mathrm{L}$ vials) and incubated for 4-7 h to generate a standard curve (a regression of oxygen consumed vs. number of larvae) from which we could estimate the rate of oxygen consumption per individual (expressed as pmol $\mathrm{O}_{2} / \mathrm{hr} /$ larva) under each experimental condition. Two control vials containing only filtered seawater (FSW) were incubated simultaneously to account for background respiration. Following incubation, larvae were removed, water was transferred to an optode cell using a gastight syringe (Hamilton Company, Reno, NV, USA) and $\mathrm{O}_{2}$ was measured using a fiber-optic oxygen meter (Microx TX3; PreSens, Regensburg, Germany). The oxygen meter was calibrated using $\mathrm{NaSO}_{3}$ solution and FSW. Additional blanks (FSW only) were used to account for instrumental drift. Differences in respiratory rates between treatments were tested using a one-way ANOVA in the statistical package Minitab (2007). We tested that data met assumptions of ANOVA (normality, homogeneity of variance).

\section{Parental effects and heritability}

We estimated variance components for larval size under highand low- $\mathrm{pCO}_{2}$ conditions by fitting generalized linear-mixed models (GLMM) using Markov chain Monte Carlo (MCMC) in the R package MCMCglmm (Hadfield, 2010; R Development Core Team, 2010), which allows the fitting of variance structures associated with pedigrees under an animal model (Kruuk, 2004). Animal models are a form of mixed-effect model used to decompose environmental and genetic effects on organismal phenotypes. They have been used to estimate the potential for evolutionary responses to environmental change in a diversity of taxa and ecological contexts (Nussey et al., 2005; Kellermann et al., 2006; Gienapp et al., 2008), and are especially powerful because they can be used in the absence of a fully crossed breeding design (Wilson et al., 2010). We estimated variance components for larval size under high and low $\mathrm{pCO}_{2}$ separately according to the model:

$$
\begin{aligned}
y= & \mu+z_{1} \text { Animal }+z_{2} \text { Dam }+z_{3} \text { Block }+\beta_{1} \text { Damsite } \\
& +\beta_{2} \text { Siresite }+\varepsilon
\end{aligned}
$$

where $\mu$ is the population mean Animal is a random effect due the additive effects of an individual's genetic makeup (additive genetic variance), and Dam is a random effect due to the additional phenotypic effects of the mother on offspring size, beyond the additive effects of her genetic makeup (i.e. maternal effects), and Block is the effect contributed by variation among each of the eight runs of the experiment (each of which lasted a week). We treated the effects of parental site of origin (Siresite and Damsite) as fixed effects, and $\varepsilon$ was a random residual error. Narrow-sense heritability $\left(h^{2}\right)$ could then be estimated as the ratio between additive genetic variance $\left(\sigma_{\mathrm{A}}^{2}\right)$ and the total phenotypic variance $\left(\sigma^{2}\right.$ тот). For larval size under high $\mathrm{pCO}_{2}$, we fitted an additional version of the model adding the fixed-effect $\beta_{3}$ Familysize, which was the mean size of larvae resulting from that cross, reared under low $\mathrm{pCO}_{2}$.

We set the priors under MCMC to partition variance equally among Dam, Animal, Block, and residual error effects. However, we also checked that other choices of priors did not 
greatly influence model outcomes. We ran the MCMC chains for 1300000 iterations, with a burn-in interval of 300000 to insure convergence. We checked for convergence by ensuring that autocorrelation values for parameters were near zero, and that there was no trend in parameter values with successive iterations after the initial burn-in period. Parameters and confidence intervals were estimated from 1000 samples of the posterior parameter distribution.

\section{Modeling}

We wished to understand how the observed genetic variance for size under high- $\mathrm{pCO}_{2}$ conditions changed predicted outcomes for S. purpuratus in the future ocean, relative to a scenario that did not include the effects of evolution. We therefore used a modeling approach to explore the effects of estimated genetic variance on larval size and the demographic response to future OA conditions. Most models of evolutionary change in a shifting environment predict the amount of phenotypic change that is expected to occur per generation. Instead, we chose to ask: when surface water $\mathrm{pH}$ reaches 7.6, given our estimates of $\sigma_{\mathrm{A}}^{2}$, how will larval size and demographic rates compare (i) with larval size and demographic rates under present conditions (ii) to estimates of future size and demographic rates made without considering the effects of adaptation (which is how projections about the effects of OA are typically made). We assumed that larval size is under stabilizing selection and that populations are currently at their optimum, and used the model of evolution in a changing environment developed by Lande \& Shannon (1996). Every generation, a changing environment increases the distance between the mean phenotype and the optimum phenotype. And every generation, the phenotype evolves toward the optimum at a rate that is proportional to the distance from the optimum, the strength of stabilizing selection, and the additive variance for the trait:

$$
\Delta Z_{t}=-\gamma \sigma_{A}^{2}\left(\bar{Z}_{t}-\theta\right)
$$

where $\sigma_{\mathrm{A}}^{2}$ is the additive genetic variance, $\gamma$ is the strength of stabilizing selection, $z_{t}$ is the mean phenotypic value for the population, and $\theta$ is the optimum phenotype. We considered values for $\sigma_{\mathrm{A}}^{2}$ from 0 to the maximum estimate of $\sigma_{\mathrm{A}}^{2}$ obtained from our animal model estimate of additive genetic variance for size under high $\mathrm{pCO}_{2}$ across both populations. We considered values of $\gamma$ ranging from 0 to $\gamma=0.0016$ because the Lande and Shannon's model requires that $(\gamma)^{*}$ $\left(\sigma_{\mathrm{A}}^{2}\right)<1$. This requirement stems from the fact that selection erodes genetic variation. It is therefore unreasonable to assume the presence of large values for genetic variance and strong stabilizing selection.

We modeled the evolution of larval size under decreasing $\mathrm{pH}$ according to a time-step model. Every generation, falling $\mathrm{pH}$ causes a decrease in mean larval size, whereas evolutionary change brings the mean phenotype back toward the optimum by an amount described by eqn 2 . In our model, in the absence of evolutionary change, the total reduction in size produced by a future $\mathrm{pH}$ of 7.6 is $-28.1 \mu \mathrm{m}$ because this was the mean reduction in size we observed in our experiment for modern larvae under future conditions. We set the number of generations for $\mathrm{pH}$ to reach 7.6 as $i$, so that each generation increasing $\mathrm{pCO}_{2}$ pushes the population mean phenotype an additional $(28.1 / i) \mu \mathrm{m}$ from the optimum phenotype $\theta$. The total reduction in size each generation due to the combined effects of evolutionary change and decreasing $\mathrm{pH}$ is therefore:

$$
\Delta \mathrm{Z}_{t}=\frac{28.1}{i}-\gamma \sigma_{A}^{2}\left(Z_{t}-\theta\right)
$$

summing across $i$ generations, the total change in phenotype between present, and the time $\mathrm{pH}$ reaches 7.6 is as follows:

$$
\begin{aligned}
\Delta Z= & \sum_{n=1}^{i}-28.1+\frac{28.1}{i}(i-1) \gamma^{1}\left(\sigma_{A}^{2}\right)^{1}-\frac{28.1}{i}(i-2) \gamma^{2}\left(\sigma_{A}^{2}\right)^{2} \\
& +\frac{28.1}{i}(i-3) \gamma^{3}\left(\sigma_{A}^{2}\right)^{3} \ldots+\frac{28.1}{i}(i-n) \gamma^{n}\left(\sigma_{A}^{2}\right)^{n}
\end{aligned}
$$

The 'evolutionary load,' or the reduction in the densityindependent population growth rate due to the deviation in the population mean from the optimum phenotype is as follows:

$$
\Delta r_{t}=(\gamma / 2)\left(\bar{Z}_{t}-\theta\right)^{2}
$$

We used eqn 5 to project the effect of this lag on mean population fitness (the density-independent growth rate, $r$ ), and compared this to the expected reduction in fitness without evolutionary change (equivalent to setting $\sigma_{\mathrm{A}}^{2}=0$ in our model). The minimum generation time for S. purpuratus is 2 years, but in our model $i$ is determined by the average turnover time (which will be greater than the minimum generation time). We considered a range of values for $i$ from $i=5$ to $i=20$, equivalent to setting the range of mean population turnover times to $2.5-10$ years if, as models predict, coastal $\mathrm{pH}$ during upwelling in the CCLME reaches 7.6 in 50 years (Gruber et al., 2012). Across the range of parameter values we considered, there was very little effect of our choice of $i$ on future larval size or S. purpuratus demographic rates (Fig. S2), so we chose to focus on results for $i=10$ for the purposes of further discussion.

As with any other modeling exercise, our approach involves several assumptions and limitations. One key assumption is that larval size is under stabilizing selection. This is probably reasonable, as it is supported by theory (which suggests positive selection on larval size and a trade-off between offspring size and number; (Vance, 1973) and empirical data from other marine larvae (Johnson et al., 2010). However, empirical data also suggest that optimal larval size varies with a host of environmental factors, including food availability (BoidronMetairon, 1988) and interspecific competition (Marshall \& Monro, 2013). The Lande and Shannon model is limited, relative to some similar models in that it does not incorporate the effects of phenotypic plasticity (Chevin et al., 2010), demographic stochasticity (Gomulkiewicz \& Holt, 1995), erosion of genetic variance by selection (Burger \& Lynch, 1995), or constraints imposed by correlations with other traits (Chevin, 2013). We chose not to include these effects for several reasons. First, we had no data on phenotypic plasticity or genetic correlations with other traits. Second, effective population sizes of S. purpuratus are very high, and 
we observed no increase in mortality in our high- $\mathrm{pCO}_{2}$ treatment, so it seems unlikely that selection would be strong enough to substantially erode genetic variance, or that the demographic stochasticity at small population sizes would play an important role in the effects of OA on this species.

\section{Results}

We collected adult S. purpuratus from two sites which experience consistent differences in the strength of upwelling and are separated by $>700 \mathrm{~km}$ (Hauri et al., 2012). Sensors deployed in the spring and summer of 2011 and the spring of 2012 show strong differences in the duration of low-pH events in the surface waters of these two regions (Fig. 1a and b). $\mathrm{pH}$ measured at each site ranged from roughly 7.6 to 8.3 , however, there is a higher frequency of low $\mathrm{pH}$ values for northern California as compared with the southern California region (Fig. 1b). This variation in upwelling intensity (i.e. low$\mathrm{pH}$ events) results in adult urchins, and presumably larvae in the water column, being exposed to different seawater $\mathrm{pH}$ regimes in an upwelling mosaic that has been characterized by a network of sensors (Chan et al. unpublished data).

When we reared 64 families created from crosses among and within these two regions under high(1210 $\mu$ atm, $\mathrm{pH}=7.60)$ and low- (424 $\mu \mathrm{atm}, \mathrm{pH}=8.02)$ $\mathrm{pCO}_{2}$ conditions (Table S2), we found that larvae reared under high $\mathrm{pCO}_{2}$ (corresponding to midcentury atmospheric $\mathrm{CO}_{2}+$ upwelling effects) were $9.6 \%( \pm 0.2 \% \mathrm{SE})$ smaller than those reared under low- $\mathrm{pCO}_{2}$ conditions $\left(F_{1,3180}=1088, P<0.0001\right)$. However, these reductions in body size were not associated with changes in metabolism: larval respiration rates did not differ among sites $\left(F_{1,20}=0.41, P=0.53\right)$ or $\mathrm{pCO}_{2}$ treatments $\left(F_{1,20}=0.02\right.$, $P=0.90$, Fig. S3). Separating results by parental site of origin, we found that offspring of northern males were $8.9 \%$ ( $\pm 0.3 \%$ SE) smaller under high $\mathrm{pCO}_{2}$, whereas offspring of southern males were $10.2 \%$ ( $\pm 0.3 \%$ SE) smaller. We found the reverse pattern when comparing the offspring of northern vs. southern females. Offspring of northern females were $11.0 \%( \pm 0.3 \% \mathrm{SE})$ smaller under high $\mathrm{pCO}_{2}$, whereas offspring of southern females were only $8.2 \%$ ( $\pm 0.3 \% \mathrm{SE})$ smaller.

To assess the capacity of S. purpuratus to evolve tolerance of high- $\mathrm{pCO}_{2}$ conditions, we estimated variance components for larval size under an animal model (Kruuk, 2004). There was substantial additive genetic variance for larval size under both high- and low- $\mathrm{pCO}_{2}$ conditions with a heritability (the proportion of phenotypic variance controlled by additive genetic effects) for size of $0.40 \pm 0.32(95 \% \mathrm{CI})$ under low- $\mathrm{pCO}_{2}$, and $0.50 \pm 0.30$ under high- $\mathrm{pCO}_{2}$ conditions (Table 1,
Fig. 2). Estimates of additive genetic variance for size under high $\mathrm{pCO}_{2}$ remained high, even after controlling for mean larval size in each family under low $\mathrm{pCO}_{2}$ (Table 1, Fig. 2). Maternal effects also controlled substantial amounts of variation in larval size under both high- and low- $\mathrm{pCO}_{2}$ conditions (Table 1, Fig. 2). The proportion of variation controlled by maternal effects was $0.29 \pm 0.19(95 \% \quad \mathrm{CI})$ under low $\mathrm{pCO}_{2}$, and $0.21 \pm 0.17(95 \% \mathrm{CI})$ under high $\mathrm{pCO}_{2}$.

We used our estimates of the total additive genetic variance present for size under high $\mathrm{pCO}_{2}$ across both populations $\left(\sigma_{\mathrm{A}}^{2}\right)$ to parameterize a model predicting the rate of evolution under changing $\mathrm{pCO}_{2}$, and the effect of evolutionary change on demographic rates (Lande \& Shannon, 1996). Our model shows that when selection on body size is weak, there is very little evolutionary change (Fig. 3a), but there is also very little effect of future OA conditions on demographic rates (Fig. 3b). However, the impact of genetic variation on predicted outcomes becomes stronger with increasing selection intensity. Under the strong selection, the effects of OA conditions on future demographic rates are much smaller when evolutionary change is taken into account, with an OA-driven decrease in population growth rate that is only half of what can be expected under the 'no evolution' scenario (equivalent to setting $\sigma_{\mathrm{A}}^{2}=0$ in our model) (Fig. 3b).

When we compared offspring of parents from the two sites we found no effect of paternal site of origin on larval size under low $\mathrm{pCO}_{2}$ (Table 1, Fig. 4). However, under high $\mathrm{pCO}_{2}, 21$ offspring of northern California sires were larger than offspring of southern California sires (Table 1, Fig. 4a). By contrast, maternal site of origin affected size under low but not high $\mathrm{pCO}_{2}$ (Table 1 , Fig. 4b).

\section{Discussion}

Adaptation from standing genetic variation has the potential to substantially alter demographic responses to environmental change (Carroll et al., 2007; Hoffmann \& Sgrò, 2011; Reed et al., 2011). In this study, we quantified genetic variation for larval body size in the ecologically important purple urchin S. purpuratus under future OA conditions. We then used these data to address two questions: (i) How are predicted effects of OA on S. purpuratus altered by incorporating the potential for evolutionary change? and (ii) Do S. purpuratus from different sites vary in their tolerance of low-pH conditions?

We observed a 9.6\% ( $\pm 0.2 \% \mathrm{SE})$ reduction in body size for larvae reared under high $\mathrm{pCO}_{2}$. Reductions in body size are often observed for larvae reared under OA conditions (Hofmann et al., 2010; Kroeker et al., 
Table 1 Variance components for larval size $(\mu \mathrm{m})$ estimated from three animal models, with animal and dam as random effects, and maternal and paternal site of origin as fixed effects: (i) under low $\mathrm{pCO}_{2}$; (ii) under high $\mathrm{pCO}_{2}$, and (iii) under high pCO mean size under low $\mathrm{pCO}_{2}$ for that family added as a fixed effect. Variance components are as follows: $V_{\mathrm{a}}-$ additive genetic variance; $V_{\text {dam }}$ - maternal effects (additional phenotypic effects of dams on offspring size beyond additive genetic effects of the maternal parent), $V_{\text {damsite }}$ - variance explained by maternal site of origin, $V_{\text {siresite }}-$ variance explained by paternal site of origin, $V_{\text {familysize }}$ - variance in size under high $\mathrm{pCO}_{2}$, explained by mean family size under low $\mathrm{pCO}_{2}, V_{\mathrm{p}}$ - phenotypic variance, and $V_{\text {block }}-$ variance among blocks (separate week-long runs of the experiment). Variance components are shown with $95 \%$ confidence intervals. Dash indicates that variance component was not significantly different from 0

\begin{tabular}{lllllllll}
\hline & $N$ & $V_{\mathrm{a}}$ & $V_{\text {dam }}$ & $V_{\text {damsite }}$ & $V_{\text {siresite }}$ & $V_{\text {familysize }}$ & $V_{\text {block }}$ & $V_{\mathrm{p}}$ \\
\hline Low $\mathrm{CO}_{2}$ size $(\mu \mathrm{m})$ & 1600 & 125 & 115 & 11.1 & - & $\mathrm{n} / \mathrm{a}$ & 254 & 542 \\
& & $(27-277)$ & $(24-213)$ & $(3.3-20.3)$ & & & $(16-648)$ & $(385-699)$ \\
High $\mathrm{CO}_{2}$ size $\left.(\mu \mathrm{m}) \mathrm{a}\right)$ & \multirow{2}{*}{1550} & 326 & 134 & - & 10.4 & $\mathrm{n} / \mathrm{a}$ & 86 & 640 \\
& & $(132-579)$ & $(25-269)$ & & $(7.4-19.8)$ & & $(12-221)$ & $(505-774)$ \\
High $\mathrm{CO}_{2}$ size $\left.(\mu \mathrm{m}) \mathrm{b}\right)$ & \multirow{2}{*}{1550} & 350 & 100 & - & 10.5 & 262 & 75 & 858 \\
& & $(147-573)$ & $(18-217)$ & & $(1.6-20.3)$ & $(100-449)$ & $(9-188)$ & $(653-1063)$ \\
\hline
\end{tabular}

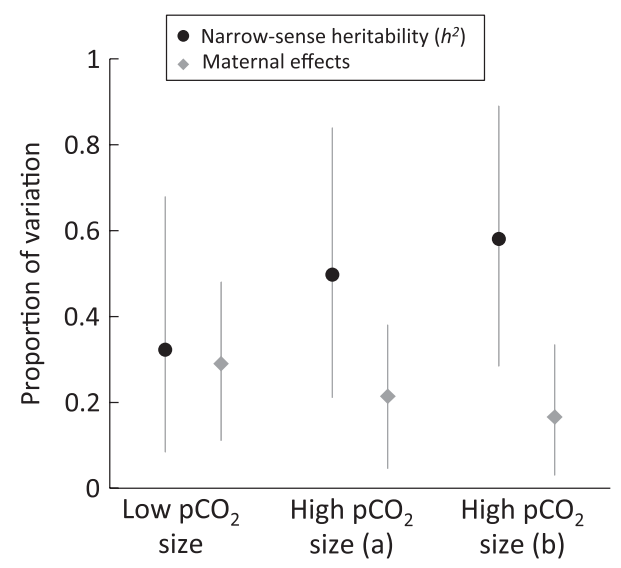

Fig. 2 Estimates obtained from animal models (Kruuk, 2004) of narrow-sense heritability $\left(h^{2}\right)$ and maternal effects (means \pm 95\% confidence intervals) for larval size in Strongylocentrotus purpuratus. Animal and dam were treated as random effects, and maternal and paternal site identity as fixed effects. For larval size under high $\mathrm{pCO}_{2}$, we also controlled for family-level variation in larval size that was unrelated to $\mathrm{CO}_{2}$ sensitivity by fitting the same model with mean larval size for that family under low $\mathrm{pCO}_{2}$ as a fixed effect. Results of this model are shown as 'high $\mathrm{pCO}_{2}$ size $(b)^{\prime}$.

2010) and are relevant to the performance of S. purpuratus in the future ocean because skeletal size is related to feeding rate (Strathmann, 1971) and risk of predation (Allen, 2008). Overall, reductions in body size have been an emergent response to climate change across multiple systems and stressors (Sheridan and Bickford 2011). However, the reductions in larval body size that we (and others) have observed represent the effects of future conditions on modern populations, absent any moderating effects of evolutionary change.

Therefore, to measure the capacity of S. purpuratus to evolve increased tolerance of OA conditions, we estimated additive genetic variance for size under high $\mathrm{pCO}_{2}$. Animal model analyses showed substantial additive genetic variance for larval size under both high- and low- $\mathrm{pCO}_{2}$ conditions (Table 1, Fig. 2), meaning that this trait can evolve. Observed genetic variance for size under high $\mathrm{pCO}_{2}$, may be due to variation among families in the effects of $\mathrm{CO}_{2}$, or merely due to variation among families in overall size (Fig. S4). However, there was still substantial additive genetic variance for size under high $\mathrm{pCO}_{2}$ after controlling for mean larval size in each family under low $\mathrm{pCO}$, suggesting that actual sensitivity to high conditions has a genetic basis. (Table 1, Fig. 2). High levels of genetic variance for size under high $\mathrm{pCO}_{2}$ are consistent with results of Pespeni et al. (2013) who found significant changes in allele frequencies for S. purpuratus larvae cultured under high $\mathrm{pCO}_{2}$, suggesting a capacity for rapid evolutionary change. We also found significant maternal effects, consistent with recent data on the importance of these effects in marine organisms (Marshall, 2008), including maternal carryover effects on offspring responses to high $\mathrm{pCO}_{2}$ (Miller et al., 2012; Parker et al., 2012).

For a trait under selection, the rate of evolutionary change will be proportional to the amount of additive genetic variance for that trait. We used our estimates of additive genetic variance for size under high $\mathrm{pCO}_{2}$ to predict rate of evolution under changing $\mathrm{pCO}_{2}$, and the effect of evolutionary change on demographic rates (Lande \& Shannon, 1996). The magnitude of evolutionary change depends on the strength of selection (the change in fitness as a function of larval size) and the amount of additive genetic variance for the trait in question. Although it is difficult to estimate the impact of larval size on fitness in natural settings, we can use our model to show how incorporating capacity for adaptation changes predicted outcomes for S. purpura- 

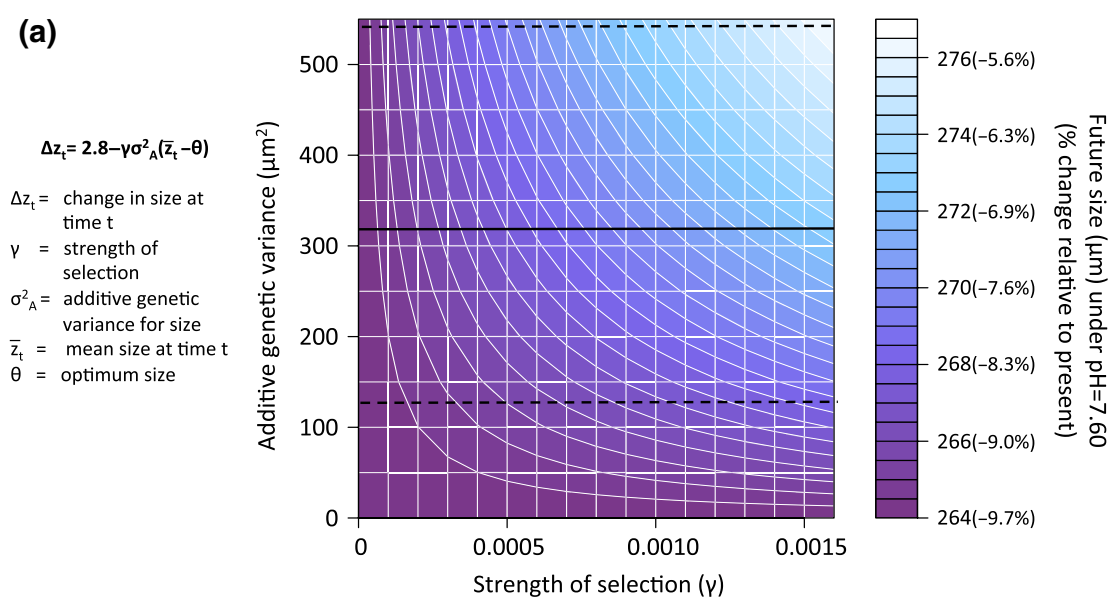

(b)

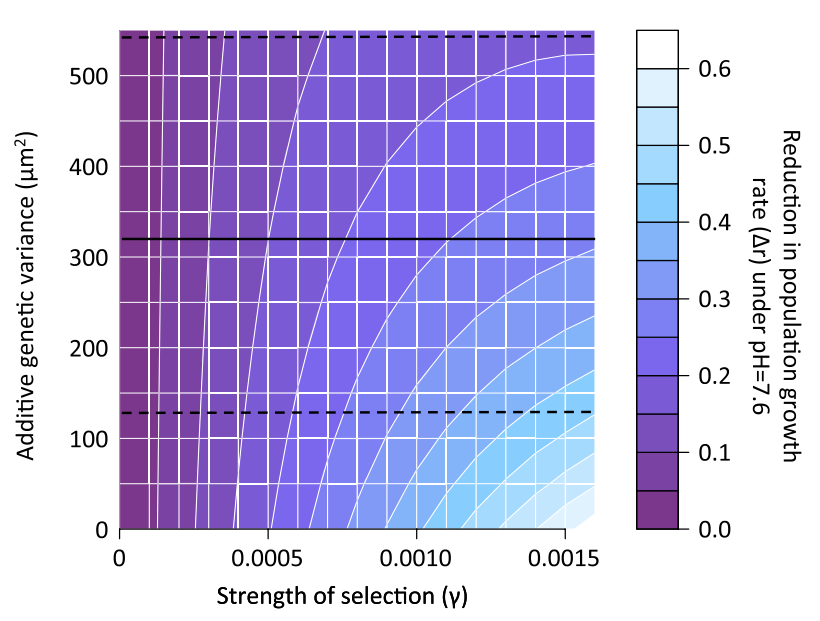

Fig. 3 Results of model estimating the effects of additive genetic variance on projections of future larval size and S. purpuratus demographic rates. (a) Projected future larval body length for $S$. purpuratus under high- $\mathrm{pCO}_{2} /$ low-pH conditions across a range of values for selection on body size and additive genetic variance for body size $\left(\sigma_{\mathrm{A}}{ }^{2}\right)$ under high-p $\mathrm{CO}_{2}$ conditions. Solid line shows estimate of $\sigma_{\mathrm{A}}{ }^{2}$ obtained from this study, dashed lines show 95\% confidence interval on that estimate. Results shown are for model where $i$ (the number of generations for $\mathrm{pH}$ to reach 7.6) is set to 10. However, model outcomes are similar for values of $i$ ranging from 5 to 20 (Fig. S2). (b) Projected reduction in density-independent population growth rate $(r)$ for $S$. purpuratus under future high-pCO $2 /$ low-pH conditions (relative to $r$ under current conditions) across a range of values for selection on body size and additive genetic variance for body size $\left(\sigma_{\mathrm{A}}{ }^{2}\right)$ under high- $\mathrm{pCO}_{2}$ conditions. Solid line shows estimate of $\sigma_{\mathrm{A}}{ }^{2}$ obtained from this study, dashed lines show $95 \%$ confidence interval on that estimate.

tus under future OA conditions across a reasonable range of selection intensities. Our model shows that when selection on body size is weak, there is very little evolutionary change (Fig. 3a), but there is also very little effect of future OA conditions on demographic rates (Fig. 3b). However, the impact of genetic variation on predicted outcomes becomes stronger with increasing selection intensity. Under strong selection (meaning that a decrease in larval size imposed by OA is highly deleterious), the OA-driven decrease in population growth rate is only half of what can be expected under the 'no evolution' scenario (Fig. 3b). Any study which projects the effects of OA by exposing modern populations to future conditions inherently assumes that there will be no evolutionary change, equivalent to setting $\sigma_{\mathrm{A}}^{2}=0$ in our model (Fig. 3). Importantly, our model shows that such studies are likely to substantially overestimate the effects of future conditions on a species like S. purpuratus with abundant genetic variation for size under high $\mathrm{pCO}_{2}$.

There was an effect of sire site of origin on larval size under high but not low $\mathrm{pCO}_{2}$ (Table 1, Fig. 4). Offspring of northern California sires were larger under high $\mathrm{pCO}_{2}$ than offspring of southern California sires (Table 1, Fig. 4a), consistent with expectations of lower sensitivity to high $\mathrm{pCO}_{2}$ in urchins from a site with stronger and more persistent upwelling. By contrast, we detected an effect of maternal site of origin on off- 

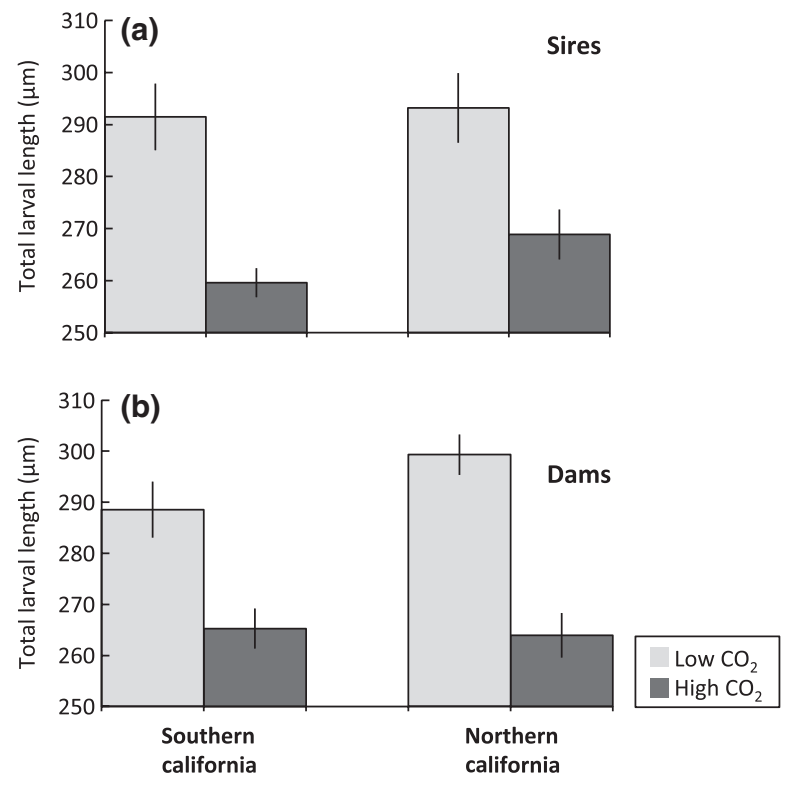

Fig. 4 Total larval length of S. purpuratus raised for 5 days under low- $\mathrm{pCO}_{2}$ and high- $\mathrm{pCO}_{2}$ conditions. (a) Mean sizes of offspring of northern vs. southern California sires $( \pm S E)$. Offspring of northern CA sires are larger than the offspring of southern $\mathrm{CA}$ sires under high $\mathrm{pCO}_{2}(\mathrm{pMCMC}=0.046)$ but not under low $\mathrm{pCO}_{2}(\mathrm{pMCMC}=0.18)(\mathrm{b})$ Mean sizes of offspring of northern vs. southern California dams. There was no effect of maternal site of origin on offspring size under high $\mathrm{pCO}_{2}$ ( $\mathrm{pMCMC}=0.81$ ), but there was an effect of maternal site of origin on offspring size under low $\mathrm{pCO}_{2}(\mathrm{pMCMC}=0.016)$.

spring size under low $\mathrm{pCO}_{2}$ but not under high $\mathrm{pCO}_{2}$ (Table 1, Fig. 4b). The effects of mothers on offspring phenotypes include both additive genetic effects and maternal effects, which are effects of the environment (e.g., greater food availability at one site) transmitted through the mother. On average, the additive genetic effects of mothers and fathers should be the same, so our results imply that there may have been environmental effects transmitted through mothers that were working in the opposite direction from genetic effects. Nevertheless, significant differences attributed to sire site of origin imply true genetic differences among sites in the response to high $\mathrm{pCO}_{2}$. Evidence for spatial and temporal adaptation to carbonate chemistry has been observed in coccolithophore algae (Beaufort et al., 2011; Smith et al., 2012), but to our knowledge, this is some of the first evidence for local adaptation to carbonate chemistry in any marine invertebrate. Our data suggest that regional differences in carbonate chemistry may act to maintain genetic variation necessary for adaptation to changing $\mathrm{pH}$. Nevertheless, the differences between the two sites in our study were also quite small; sire site of origin explained $<2 \%$ of the total variation in offspring size. This is consistent with the biology of S. purpuratus, which has a long planktonic larval duration ( $>4$ weeks, Strathmann, 1978). Large amounts of dispersal tend to homogenize populations, and indeed, S. purpuratus shows near panmixia for neutral markers across most of its geographic range (Edmands et al., 1996), although recent work also demonstrates latitudinal clines in some (presumably adaptive) alleles (Pespeni et al., 2012). More data are needed for S. purpuratus and other species to understand whether the differences we observed between the two sites in our study are representative of a larger pattern for species inhabiting the California Current Large Marine Ecosystem. In particular, even in invertebrates with high gene flow, relatedness of recruits and postsettlement mortality may drive patterns of small-scale variation among sites and microhabitats that are not representative of regional patterns (Rand et al., 2002; Eldon \& Wakeley, 2009).

Our estimate of the heritability of size $\left(h^{2}=0.50\right)$ for S. purpuratus larvae under high- $\mathrm{pCO}_{2}$ conditions is relatively high, but well within the range of heritabilities observed for morphological traits in other invertebrates (Mousseau \& Roff, 1987). However, our estimate is also substantially higher than the two estimates of $h^{2}$ for size under high $\mathrm{pCO}_{2}$ obtained for other metazoans $\left(h^{2}=0.0\right.$ and 0.09 for a mussel and another urchin, respectively, Sunday et al., 2011). Interestingly, Sunday et al. obtained estimates of $\sigma_{\mathrm{A}}{ }^{2}$ for size in the red urchin $S$. franciscanus larvae that were very similar to our estimates for S. purpuratus, but estimates of total phenotypic variance that were substantially higher, depressing their estimates of $h^{2}$. This highlights the importance of laboratory rearing methods in estimating $h^{2}$, as different methodologies can introduce different levels of environmental heterogeneity into larval cultures, thereby inflating or deflating levels of phenotypic variance observed within cultures in the laboratory.

End-century atmospheric $\mathrm{CO}_{2}$ concentrations are expected to reach $788 \mathrm{ppm}$ under business as usual scenarios, resulting in a mean surface ocean $\mathrm{pH}$ of 7.8 (Orr et al., 2005). However, models suggest that these conditions will be reached sooner in upwelling environments, with a mean nearshore $\mathrm{pH}$ of 7.8 in the California Current ecosystem by 2050 and a $\mathrm{pH}$ of 7.6 during upwelling events (Gruber et al., 2012). Laboratory studies across a wide range of taxonomic groups demonstrate negative effects of these nearfuture conditions. However, our data indicate the potential for substantial short-term evolution in response to high $\mathrm{pCO}_{2}$, and substantial changes in predicted outcomes for S. purpuratus, after accounting for the potential for evolutionary change. As one of the first studies to measure quantitative genetic variation for response to high $\mathrm{pCO}_{2}$, our work high- 
lights the importance of considering the potential for adaptation when forecasting the biological impacts of climate change.

\section{Acknowledgments}

Oceanographic data from the study sites were collected as part of a regional $\mathrm{pH}$ monitoring effort (OMEGAS consortium http://omegas.science.oregonstate.edu/) and supported by U.S. National Science Foundation (NSF) award OCE 1040960 to GEH. Oceanographic data for the SB site was provided by Dr. P. Matson and Professor L. Washburn. Dr. F. Chan generously provided us with oceanographic data for the VD and LOL sites and Professor T. Hill of the Bodega Marine Lab Ocean Acidification Research group (BOAR) graciously provided us with oceanographic data for the BR site. Dr. E. Kuo provided crucial fieldwork assistance on this project. We wish to thank Professor E. Sanford for advice on collection sites, Dr. P. Yu for advice on larval culturing and maintenance, Professor M.A. Sewell for reading a version of the manuscript, and C. Pierre for animal collection. L. Kapsenberg, Dr. G. Dilly, P. DuarteQuiroga, and Dr. K. Savicki provided logistical and laboratory support. E. Fabris, C. Armstrong, M. Shea, A. Masci, and Dr. K. Langlois assisted with larval measurements. MWK and GEH were supported by funds from the University of California in support of a Multicampus Research Program, Ocean Acidification: A Training and Research Consortium (http://oceanacidification.msi.ucsb.edu/) to GEH. GEH and JLPG were partially supported by OCE 1040960 .

\section{References}

Allen JD (2008) Size-specific predation on marine invertebrate larvae. The Biological Bulletin, 214, 42-49.

Beaufort L, Probert I, De Garidel-Thoron T et al. (2011) Sensitivity of coccolithophores to carbonate chemistry and ocean acidification. Nature, 476, 80-83.

Bell G, Gonzalez A (2009) Evolutionary rescue can prevent extinction following environmental change. Ecology Letters, 12, 942-948.

Boidron-Metairon IF (1988) Morphological plasticity in laboratory-reared echinoplutei of Dendraster excentricus (Eschscholtz) and Lytechinus variegatus (Lamarck) in response to food conditions. Journal of Experimental Marine Biology and Ecology, 119, $31-41$.

Bradshaw WE, Holzapfel CM (2001) Genetic shift in photoperiodic response correlated with global warming. Proceedings of the National Academy of Sciences of the United States of America, 98, 14509-14511.

Burger R, Lynch M (1995) Evolution and extinction in a changing environment - a quantitative-genetic analysis. Evolution, 49, 151-163.

Carroll SP, Hendry AP, Reznick DN, Fox CW (2007) Evolution on ecological timescales. Functional Ecology, 21, 387-393.

Chevin L-M (2013) Genetic constraints on adaptation to a changing environment. Evolution, 67, 708-721.

Chevin LM, Lande R, Mace GM (2010) Adaptation, plasticity, and extinction in a changing environment: towards a predictive theory. Plos Biology, 8, e1000357.

Collins S, Bell G (2006) Evolution of natural algal populations at elevated $\mathrm{CO}_{2}$. Ecology Letters, 9, 129-135.

Dickson AG, Sabine CL, Christian JR (eds) (2007) Guide to Best Practices for Ocean $\mathrm{CO}_{2}$ Measurements. PICES special publications, 191p. Available at:http://cdiac.ornl. gov/oceans/Handbook_2007.html (accessed 4 January 2012).

Doney SC, Ruckelshaus M, Duffy JE et al. (2012) Climate change impacts on marine ecosystems. Annual Review of Marine Science, 4, 11-37.

Edmands S, Moberg PE, Burton RS (1996) Allozyme and mitochondrial DNA evidence of population subdivision in the purple sea urchin Strongylocentrotus purpuratus. Marine Biology, 126, 443-450.

Eldon B, Wakeley J (2009) Coalescence times and FST under a skewed offspring distribution among individuals in a population. Genetics, 181, 615-629.
Eliason EJ, Clark TD, Hague MJ et al. (2011) Differences in thermal tolerance among sockeye salmon populations. Science, 332, 109-112.

Etterson JR, Shaw RG (2001) Constraint to adaptive evolution in response to global warming. Science, 294, 151-154.

Fangue NA, O'donnell MJ, Sewell MA, Matson PG, Macpherson AC, Hofmann GE (2010) A laboratory-based, experimental system for the study of ocean acidification effects on marine invertebrate larvae. Limnology and Oceanography-Methods, 8, $441-452$.

Foo SA, Dworjanyn SA, Poore AGB, Byrne M (2012) Adaptive capacity of the habitat modifying sea urchin Centrostephanus rodgersii to ocean warming and ocean acidification: performance of early embryos. PLOS ONE, 7, e42497.

Franks SJ, Sim S, Weis AE (2007) Rapid evolution of flowering time by an annual plant in response to a climate fluctuation. Proceedings of the National Academy of Sciences of the United States of America, 104, 1278-1282.

Frieder CA, Nam SH, Martz TR, Levin LA (2012) High temporal and spatial variability of dissolved oxygen and $\mathrm{pH}$ in a nearshore California kelp forest. Biogeosciences Discussion, 9, 4099-4132.

Gienapp P, Teplitsky C, Alho JS, Mills JA, Merilä J (2008) Climate change and evolution: disentangling environmental and genetic responses. Molecular Ecology, 17, $167-178$.

Gomulkiewicz R, Holt RD (1995) When does evolution by natural-selection prevent extinction. Evolution, 49, 201-207.

Gomulkiewicz R, Houle D (2009) Demographic and genetic constraints on evolution. American Naturalist, 174, E218-E229.

Gruber N, Hauri C, Lachkar Z, Loher D, Frölicher TL, Plattner G-K (2012) Rapid progression of ocean acidification in the California current system. Science, 337, 220-223.

Hadfield JD (2010) MCMC methods for multi-response generalized linear mixed models: the MCMCglmm R package. Journal of Statistical Software, 33, 1-22.

Harley CDG, Hughes AR, Hultgren KM et al. (2006) The impacts of climate change in coastal marine systems. Ecology Letters, 9, 228-241.

Hauri C, Gruber N, Vogt M et al. (2012) Spatiotemporal variability and long-term trends of ocean acidification in the California Current System. Biogeosciences Discussion, 9, 10371-10428.

Hedrick PW (2006) Genetic polymorphism in heterogeneous environments: the age of genomics. Annual Review of Ecology Evolution and Systematics, 37, 67-93.

Hoffmann AA, Sgrò CM (2011) Climate change and evolutionary adaptation. Nature, 470, 479-485.

Hoffmann AA, Hallas RJ, Dean JA, Schiffer M (2003) Low potential for climatic stress adaptation in a rainforest DROSOPHILA species. Science, 301, 100-102.

Hofmann GE, Barry JP, Edmunds PJ, Gates RD, Hutchins DA, Klinger T, Sewell MA (2010) The effect of ocean acidification on calcifying organisms in marine ecosystems: an organism to ecosystem perspective. Annual Review of Ecology, Evolution, and Systematics, 41, 127-147.

Hofmann GE, Smith JE, Johnson KS et al. (2011) High-frequency dynamics of ocean pH: a multi-ecosystem comparison. PLoS ONE, 6, e28983.

Hughes AR, Inouye BD, Johnson MTJ, Underwood N, Vellend M (2008) Ecological consequences of genetic diversity. Ecology Letters, 11, 609-623.

IPCC (2007) Contribution of Working Groups I, II and III to the Fourth Assessment Report of the Intergovernmental Panel on Climate Change. In: Core Writing Team. (eds Pachauri RK, Reisinger A) pp 104, IPCC, Geneva, Switzerland.

Johnson DW, Christie MR, Moye J (2010) Quantifying evolutionary potential of marine fish larvae: heritability, selection, and evolutionary constraints. Evolution, 64, 2614-2628.

Kellermann VM, Heerwaarden BV, Hoffmann AA, Sgro CM (2006) Very low additive genetic variance and evolutionary potential in multiple populations of two rainforest Drosophila species. Evolution, 60, 1104-1108.

Kelly MW, Hofmann GE (2012) Adaptation and the physiology of ocean acidification. Functional Ecology, doi: 10.1111/j.1365-2435.2012.02061.x. [Epub ahead of print].

Kelly MW, Sanford E, Grosberg RK (2012) Limited potential for adaptation to climate change in a broadly distributed marine crustacean. Proceedings of the Royal Society B-Biological Sciences, 279, 349-356.

Kroeker KJ, Kordas RL, Crim RN, Singh GG (2010) Meta-analysis reveals negative yet variable effects of ocean acidification on marine organisms. Ecology Letters, 13, $1419-1434$.

Kruuk LEB (2004) Estimating genetic parameters in natural populations using the 'animal model'. Philosophical Transactions of the Royal Society of London Series BBiological Sciences, 359, 873-890.

Lande R, Shannon S (1996) The role of genetic variation in adaptation and population persistence in a changing environment. Evolution, 50, 434-437. 
Lohbeck KT, Riebesell U, Reusch TBH (2012) Adaptive evolution of a key phytoplankton species to ocean acidification. Nature Geoscience, 5, 346-351.

Lynch M, Walsh B (1998) Genetics and Analysis of Quantitative Traits, Sinauer Associates, Sunderland, MA.

Marsh AG, Manahan DT (1999) A method for accurate measurements of the respiration rates of marine invertebrate embryos and larvae. Marine Ecology-Progress Series, 184, 1-10.

Marshall DJ (2008) Transgenerational plasticity in the sea: context-dependent maternal effects across the life history. Ecology, 89, 418-427.

Marshall DJ, Monro K (2013) Interspecific competition alters nonlinear selection on offspring size in the field. Evolution, 67, 328-337.

Martz TR, Connery JG, Johnson KS (2010) Testing the honeywell durafet for seawater $\mathrm{pH}$ applications. Limnology and Oceanography-Methods, 8, 172-184.

Miller GM, Watson S-A, Donelson JM, Mccormick MI, Munday PL (2012) Parental environment mediates impacts of increased carbon dioxide on a coral reef fish Nature Climate Change, 2, 858-861.

Minitab (2007) Minitab 15 Statistical Software, Minitab, Inc, State College, PA. (www. minitab.com).

Mitchell KA, Sgro CM, Hoffmann AA (2011) Phenotypic plasticity in upper thermal limits is weakly related to Drosophila species distributions. Functional Ecology, 25, 661-670.

Mitchell-Olds T, Willis JH, Goldstein DB (2007) Which evolutionary processes influence natural genetic variation for phenotypic traits? Nature Reviews Genetics, 8, 845-856.

Mousseau TA, Roff DA (1987) Natural-selection and the heritability of fitness components. Heredity, 59, 181-197.

Nussey DH, Postma E, Gienapp P, Visser ME (2005) Selection on heritable phenotypic plasticity in a wild bird population. Science, 310, 304-306.

Orr JC, Fabry VJ, Aumont O et al. (2005) Anthropogenic ocean acidification over the twenty-first century and its impact on calcifying organisms. Nature, 437, 681-686.

Parker LM, Ross PM, O'connor WA, Borysko L, Raftos DA, Portner HO (2012) Adult exposure influences offspring response to ocean acidification in oysters. Global Change Biology, 18, 82-92.

Pearse JS (2006) Perspective - ecological role of purple sea urchins. Science, 314, 940-941.

Pespeni MH, Garfield DA, Manier MK, Palumbi SR (2012) Genome-wide polymorphisms show unexpected targets of natural selection. Proceedings of the Royal Society B-Biological Sciences, 279, 1412-1420.

Pespeni MH, Sanford E, Gaylord B et al. (2013) Evolutionary change during experimental ocean acidification. Proceedings of the National Academy of Sciences, 110, 6937-6942.

Pistevos JCA, Calosi P, Widdicombe S, Bishop JDD (2011) Will variation among genetic individuals influence species responses to global climate change? Oikos, 120, 675-689.

R Development Core Team(2010) R: A Language and Environment for Statistical Computing. R Foundation for Statistical Computing. Vienna, Austria.

Rand DM, Spaeth PS, Sackton TB, Schmidt PS (2002) Ecological genetics of Mpi and Gpi polymorphisms in the acorn barnacle and the spatial scale of neutral and nonneutral variation. Integrative and Comparative Biology, 42, 825-836.

Reed TE, Schindler DE, Hague MJ, Patterson DA, Meir E, Waples RS, Hinch SG (2011) Time to evolve? Potential evolutionary responses of fraser river sockeye salmon to climate change and effects on persistence. PLOS ONE, 6, e20380.

Sanford E, Kelly MW (2010) Local adaptation in marine invertebrates. Annual Review of Marine Science, 3, 509-535.

Sheridan JA, Bickford D (2011) Shrinking body size as an ecological response to climate change. Nature Climate Change, 1, 401-406.

Smith HEK, Tyrrell T, Charalampopoulou A et al. (2012) Predominance of heavily calcified coccolithophores at low $\mathrm{CaCO}_{3}$ saturation during winter in the Bay of Biscay. Proceedings of the National Academy of Sciences, 109, 8845-8849.

Strathmann RR (1971) The feeding behavior of planktotrophic echinoderm larvae: mechanisms, regulation, and rates of suspensionfeeding. Journal of Experimental Marine Biology and Ecology, 6, 109-160.

Strathmann R (1978) Length of pelagic period in echinoderms with feeding larvae from the Northeast Pacific. Journal of Experimental Marine Biology and Ecology, 34, 23-27.

Strathmann MF (1987) Reproduction and Development of Marine Invertebrates of the Northern Pacific Coast: Data and Methods for the Study of Eggs, Embryos, and Larvae, Seattle, University of Washington Press, Seattle, WA.

Sunday JM, Crim RN, Harley CDG, Hart MW (2011) Quantifying rates of evolutionary adaptation in response to ocean acidification. PLoS ONE, 6, e22881.
Vance RR (1973) On reproductive strategies in marine benthic invertebrates. The American Naturalist, 107, 339-352.

Visser ME (2008) Keeping up with a warming world; assessing the rate of adaptation to climate change. Proceedings of the Royal Society Biological Sciences Series B, 275, 649-659.

Walters RJ, Blanckenhorn WU, Berger D (2012) Forecasting extinction risk of ectotherms under climate warming: an evolutionary perspective. Functional Ecology, 26, 1324-1338.

Wilson AJ, Réale D, Clements MN et al. (2010) An ecologist's guide to the animal model. Journal of Animal Ecology, 79, 13-26.

Yu PC, Matson PG, Martz TR, Hofmann GE (2011) The ocean acidification seascape and its relationship to the performance of calcifying marine invertebrates: laboratory experiments on the development of urchin larvae framed by environmentally-relevant $\mathrm{pCO}_{2} / \mathrm{pH}$. Journal of Experimental Marine Biology and Ecology, 400, 288-295.

\section{Supporting Information}

Additional Supporting Information may be found in the online version of this article:

Fig. S1 Cross design modified from Kelly \& Hofmann, 2012. We collected adult purple urchins (Strongylocentrotus purpuratus), from populations at two sites in California, USA (inset), thought to differ in their carbonate chemistry regimes. In the laboratory, we crossed each male with two females from his own sites, and two females from the opposite site ( $N=8$ males/site, 15 females/sites), and then spilt embryos from each cross into high- and low- $\mathrm{pCO}_{2}$ rearing conditions.

Fig. S2 Projected future larval body length and change in density-independent growth rate $(r)$ under high- $\mathrm{pCO}_{2}$ conditions across a range of values for selection on body size $(\gamma)$, additive genetic variance for body size $\left(\sigma_{\mathrm{A}}{ }^{2}\right)$, and number of generations to reach $\mathrm{pH}=7.6$ (i). Model outcomes are similar values of $i$ ranging from 5 to 20 .

Fig. S3 Larval respiration rates (pmol $\mathrm{O}_{2} / \mathrm{hr} /$ larva) for offspring of parents from two sites reared under high and low $\mathrm{pCO}_{2}$. Two-way ANOva revealed no effect of site $\left(F_{1,20}=0.41, P=0.53\right) \mathrm{pCO}_{2}$ level $\left(F_{1,20}=0.02, P=0.90\right)$ or $\mathrm{pCO}_{2} \mathrm{X}$ site interaction $\left(F_{1,20}=0.13, P=0.72\right)$ on respiration rate.

Fig. S4 Hypothetical box plots showing the distribution of larval sizes for four sires under high and low $\mathrm{pCO}_{2}$. In (a), variation in size under high $\mathrm{pCO}_{2}$ is driven by variation among families in overall size. In (b), variation in size under high $\mathrm{pCO}_{2}$ is driven by variation among families in sensitivity of growth to high $\mathrm{pCO}_{2}$.

Table S1. Cross design.

Table S2. Water chemistry and carbonate parameters for larval culturing. $\mathrm{pH}$ total alkalinity (TA), salinity, and temperature were the measured parameters, and the remaining parameters were calculated in CO2SYS. $\mathrm{pH}$ was measured in each larval culture vessel each day of the experiment, TA was measured in each of the mixing reservoirs for each day of the experiment. Mean values \pm SD are shown for each week of the experiment. 